\title{
Research and Exploration on the Classification Management and Guidance of Local Applied Universities in the Perspective of Niche Theory
}

\author{
Dong-song Chen \\ Department of Teaching Affairs \\ JiLin Institute of Chemical Technology \\ JiLin, China \\ dongsongchen@163.com,
}

\author{
Guang-ping Yan* \\ Center of Faculty Development \\ JiLin Institute of Chemical Technology \\ JiLin, China \\ ygp72@163.com
}

\begin{abstract}
Using niche theory and analytic methods in ecology, this research analyzed the developing trend in classification, management and guidance about Local Application-oriented Universities. At first, this paper analyzed top-level design, educational ecology, location, transformation development about classification and management in Local Applied University. Then, starting from the connotation of niche theory, it put forward effective, scientific and reasonable countermeasures and suggestions, which have important practical significance for national and regional higher education structural optimization. The result emphasized on providing references for highlighting the characteristics and advantages of Local Application-oriented Universities. The conclusion reflected the development value and promoting further development.
\end{abstract}

Keywords-Niche Theory; Local Applied University; Classification Management and Guidance; Research and Exploration

\section{INTRODUCTION}

With the rapid development of economy, society and technology, Chinese Higher Education has achieved a leap development from elitism to popularization. The number of colleges and universities is increasing, and the needs of diversified and characteristics are increasingly obvious. The demands for talents are increasing. Therefore, the rational location, classification management and guidance of higher education become the key to achieve their scientific development and also an important proposition of higher education development. The classification management of higher education will affect the developing orientation, the talent training target, direction of future development, it is the basis and direction about achieving the developing strategies, efficient management, its own characteristics, is the goals of continuous efforts, hard work, forge ahead in Higher Education So, the rational orientation, classification management and guidance of colleges and universities have become the key to the realization of their scientific development. It is also an important proposition in the development of higher education.

The Nineteenth People's Congress indicates that higher education has entered a new era and opened a new journey, and constructing an educational power is the basic project of the

Comparative Study about the Classification Management and Guidance of the Local Applied Universities in 2017.
Chinese great nation. In the new era, the need for higher education is more urgent than ever, and the thirst for scientific knowledge and excellent talents is stronger than ever. At the same time, quality is the time proposition of the higher education in 21th Century, which will push higher education into a new stage of connotative development. Therefore, based on the current scale and diversification of higher education development, we need to take the connotative developing path to further improve the quality of higher education and personnel training. It requires all the colleges and universities to be classification management and guide according to the current social developing needs, which combined with their own advantages and characteristics to identify the developing orientation, can reflect the principle of independence, practice, development and characteristics, and promote the healthy development of different types of Higher Education.

As early as in 1993, in the outline of Chinese education reform and development, had put forward "establishing the classification standards of higher education and the corresponding policies and measures, making all kinds of schools work in a rational division and making their own characteristics on their own levels". In 2010, in the outline of the national medium and long term educational reform and development plan (2010 to 2020), had put forward the ideas of establishing the classification system of universities and implementing classified management. In 2017, in the "development" of national education in 13th Five-Year "plan" had also clearly put forward the structural reform of education as the main line of development, promote the development of higher education classification, based on the orientation of talent cultivation, we had established the classification system of higher education, it is an important measure to promote the scientific orientation and development.

For local colleges and universities, the document 'the Ministry of education, the national development and Reform Commission, the Ministry of Finance on the guiding part of local colleges and universities to change the application type of guidance" in October 2015 ("[2015]7) pointed out that we should further promote the transformation development, clearly positioning of training applied technical talents and the responsibilities of the mission, it will be in a reasonable position to put the classification management and guidance into 
the focusing point, it is imperative to promote the classification of higher education management and guidance, which is more clearly not only conducive to Chinese higher education classification level--the more sophisticated and diversified development, and but also has very important significance for the formation of science and the reasonable development of higher education and management system.

\section{The Conception And ConNotation of Niche} THEORY

The niche is a basic conception in the traditional ecology, is the spatial position and functional relationship about each individual or population in the community, indicating the necessary minimum threshold of habitat for the survival of each species in the ecosystem, also known as Tanglewood division principle. Grinnell (J.Gri-nell) created in 1924 at first and emphasized the space conception and its significance in the region. Elton (Charles Elton) will further increase the developing connotation in 1927, determine the biological effect and status in the community, and mainly emphasize on the nutrient relationship between other species and organisms. In natural environment, there are different kinds of organisms in every specific location. Their activities and relationships depend on their special structure, physiology and behavior, so they have their own unique niche. The conception was originally used to produce research on the competitive relationship among species in the content, the principle mainly refers to the biological communities or ecosystems, each species have its own role and status, which occupy a certain space, have some functions. The species or population in natural ecosystem can only be extended only when they live in suitable microenvironment. With the development of organisms, they can change their niche. The phenomenon of niche is universal for all life phenomena. It is applicable not only to the biological world (including animals, plants, microbes), but also to people (including group, society and country) [1].

Popularly speaking, niche is a specific ecological location that has formed in the long evolutionary process of organisms, and has stable living resources in a certain time and space, so as to gain the greatest survival advantage. Including niche overlap theory, niche mobile theory, niche separation theory and spiral theory of ecological succession, niche is not only suitable for natural subsystems, but also for functional and structural units in social and economic subsystems.

To implement classified management and guidance of Local Application-oriented University, we can use this theory, analyze the environment and developing trend, and find the developing position and space in the economic society, lay the foundation for playing its role better.

III. The InEXoRABle TREND OF THE IMPLEMENTATION OF Classified Management and GuidanCE in LOCAL APPLIED UNIVERSITIES

The implementation of the classification management and guidance of the Local Applied University is determined by its own functional division of labor, the training of talents and the orientation of running a school[2]. Local Applied University mainly train and transport large quantities of high quality talents for regional economic development, to train modern engineers and managers who are facing the production and management, which including theoretical foundation, strong sense of innovation, higher quality of practice and comprehensive quality, training to adapt to the demands of new technology, the development of new industries, talents with the characteristics of innovation, and internationalization, it is different from the researching colleges and universities, but also different from the higher vocational technical colleges, only to guide the implementation of classification and management, be able to give full play to the advantages, the Local Applied University can find its orientation, highlight the characteristics, lay the foundation for its better development.

The implementation of classified management and guidance in Local Applied Universities is determined by the needs of the economic and social development in the new era[3]. Since the Nineteenth Party's Era, the economic and social development in contemporary China is changing rapidly. The development of higher education has entered a new era of connotative development. It has opened a new path and has also put forward higher requirements for universities. Because the nature of social development leads the direction of higher education development and social needs drive the development of higher education, the social division of labor will be thinner and thinner, the requirements of human resources, scientific and technological achievements, university services are diversified in terms of varieties, specifications, quality and level etc..[4] Based on this, it is necessary for colleges and universities to make strategic choices in accordance with the needs of economic and social development. Therefore, when implementing the classified management and guidance of Local Application-oriented Universities, we must closely follow the pulse of the times and social development, and promote better development combined with the reality of our own development.

The implementation of classified management and guidance in Local Applied Universities is to optimize the allocation of higher education resources and it is up to adapt to social competition and service. In the process of development, must make their own abilities to gain more conducive for the development of educational resources, to achieve the functions of scientific research, personnel training and university service, constantly optimizing service is realized in the competition, and constantly improve the competitive level in service[5]. Because of the characteristics of competition and service, will make higher education resource allocation optimization present a dynamic and changeable curve, which requires Local Applied University in accordance with its own characteristics, the implementation of classification management, strengthen the close ties between economy and society, strive for better and more conducive to their development of educational resources, and the expansion of school autonomy, pay attention to the connotation of development and play a greater role.

Furthermore, according to the 'List of National Colleges and Universities in 2017" issued by the Ministry of Education, by the end of May 31th, 2017, there were 2914 higher universities in China, more than 35 last year. There are 2631 higher institutions (including 265 independent colleges), and 
283 adult higher schools. According to the latest data released by the National Bureau of statistics and the Ministry of education, the total number of college students in China is 26958 thousand, 7950 thousand recent college graduates, 7486 thousand general college enrollment. There are 1.9593million college students in the country. At this time, scale, structure, elements and levels of Chinese Higher Education system have undergone great changes, it is an important work to guide the accurate positioning scientifically, reasonably and efficiently, is also inevitable trend of development, not only has a role in promoting the implementation of the developing value, but also has important practical significance for promoting the development of regional higher education.

\section{The Countermeasures and SugGestions ON THE} Classification ManageMENT AND GUIDANCE OF THE LOCAL APPLIED UNIVERSITY

The Local Applied University is an important part of Chinese Higher Education, the adaptation to the environment of economy, society and ecology is a necessary condition for its survival and development. Therefore, this article mainly put forward countermeasures and suggestions of classified management and guidance of Local Applied University from the perspective of niche theory, makes it in a dynamic balance, and realizes the innovation in self-adjustment, actively realize the benign interaction between Local Applied University and ecological system, and promote its sustainable development.

\section{A. The top-level design--overall designing the policy and system}

At present, there are nearly three thousand common institutions of higher learning in our country. After continuous optimization and reorganization, a complex system has been formed[6]. From the types of applications, it can be divided into academic institutions, applied colleges and universities, and the applicable types, can be divided into several sub-types, different types, different levels of colleges and universities have different missions, vision, positioning, targets and functions, we can only design the overall scientific, reasonable and political system in order to guide the local applied university, identify the location, in order to meet the needs of economic and social development of a multi-type and multilevel talents.

\section{B. The educational ecology--maintaining diversity and creating educational ecological environment}

To create an educational ecological environment, it is conducive to the development of local applied universities, that is to maintain diversity of local applied university ecosystems, and diversity is an important characteristic of higher education ecosystem. Diversification has become an important trend in the development of higher education. Local applied universities can be divided into applied research type (applied basic type), applied type (applied technology type) and applied skillful type (applied teaching type), which is also determined and demanded by the diversity of social needs. In this way, the resources and power of its development can be obtained. At the same time, the establishment of a fair competitive environment and the mechanism continuing to "move forward", establishing the competitive allocation of resources in different types and different levels of colleges and universities in the policy, creating a leading diversified development of local applied university environment in fair competition, is of great significance to promote the connotation construction and the development of university.

\section{Guide the orientation-- guiding the rational orientation and clearing the characteristics and mission of the university}

In the level of guidancing positioning, first of all, we should formulate the vision developing plan, leading the orientation. the provincial education administrative departments should strengthen the overall planning and management of regional higher education and formulate development planning of regional economic and social development of higher education, clear the structural adjustment about the objectives and requirements, guiding the scientific orientation and characteristic development of local applied university.

Secondly, we should formulate policies and systems for balanced development and guide the positioning. Clearly specify the tasks, responsibilities, levels and development paths of local applied universities, and guide schools to transfer the key points to connotation construction and characteristic development, and then scientifically carry out target positioning, discipline positioning and scale positioning. To formulate the key standards for the setting and evaluation of local applied universities and take a comprehensive consideration of the input and output, the level and the characteristics and so on, guide the scientific orientation.

Thirdly, provide the full and objective information and guide the positioning. The education administrative departments should establish a relatively perfect information management system, further improve the information collection, collation, analysis and dissemination of the university education system, release information in a timely manner, give full play to the role of experts of educational policy, highlight the university characteristics and missions, guide the scientific and reasonable positioning of university.

\section{Transformation and Development -- promoting the transformation and development in an all-round way and strengthen the target orientation}

The economic transformation and development in our country, the optimization and upgrading of the industrial structure and the new scientific and technological revolution caused by information technology, these urgently need to be supported by apply technical talents. The outline of the national medium and long term educational reform and development plan (2010-2020 years) put forward: "we should optimize disciplines, majors, levels and types, and expand the training scale of applied, compound and skilled talents."[7] The key working points of Ministry of education pointed out, study and formulate the guiding opinions on the transformation and development of local colleges and universities, start the implementation of the national and provincial reform pilot, guide a number of undergraduate 
colleges and universities to transit to the application of higher school[8], which means that under the impetus of the government, higher education in China will enter a period of adjustment about the new structure.

\section{CONCLUSION}

How to adapt to economic and social development, to achieve the matching of higher education and economic structure, develop more and more high-level technical talents, these are the basic requirements of higher education and the society, as an important force in higher education, Local Application-oriented Universities only actively adapt to the new requirements of economic and social development, promote the restructuring and developing, strengthen comprehensive goal orientation, cultivate the applied technical talents who are not only master modern science and technology, but also get training system, realize the transformation from teaching oriented university to the applied technology university, we can better fulfill the responsibilities of position and the role of local applied universities adapting to economic, social development and social services. It can further provide for the security of implementing the management and guidance of university classification.

\section{REFERENCES}

[1] https://baike.baidu.com/Niche rule [EB OL].

[2] Li Qiang, Wei Congcong, on the Logical Basis of Personalized Development Planning for Colleges and Universities Based on "classified management" [J], education and teaching research, 2016 (7): 1. "In Chinese"

[3] Ari and Eero, J. Provincial University of Lapland: Collab - orating for regional Development[J]. Higher Education of Man - agrement and Policy, 2008, 20(2):115 -123.

[4] Liu Xiang-dong etc, An Empirical Study on the Classification of Higher Colleges and Universities --Analysis Based on 75 Colleges and Universities Directly under the Ministry of Education and 19 Local Construction Universities[J].Tsinghua Journal of Education,2010,(8):4551. "In Chinese"

[5] Zhou Zhihu, Hu Xiaohui, Chen Hongjun, Research on the Development Orientation of Different Types of Colleges and Universities in Anhui Province [J], 2007 (9): 19. "In Chinese"

[6] Jaana and Francisco,J. Higher Education Institutions and Regional Mission: Lessons Learnt from the OECD Review Project [J]. Higher Education Policy,2008,(21):217 - 224.

[7] Jiang Wen-zhao, The Classification Development of Colleges and Universities in China: Block and strategy[J]. Journal of Henan Institute of Education (PHILOSOPHY AND SOCIAL SCIENCE EDITION), 2015,(1):70-73. “In Chinese”

[8] He Wanguo, Cai Zongmo, Yang Zhengqiang, Research on the Development of Classified Colleges and Universities in China[J], Chinese Higher Education Research, 2016 (2): 65. “In Chinese” 